\title{
Nutritional implications for quality of life in bladder cancer survivors
}

\author{
Charles J. Rosser \\ Department of Surgery \& Samuel Oschin Comprehensive Cancer Institute, Cedars-Sinai Medical Center, Los Angeles, CA, USA \\ Correspondence to: Charles J. Rosser, MD, MBA, FACS. Department of Surgery \& Samuel Oschin Comprehensive Cancer Institute, Cedars-Sinai \\ Medical Center, 8700 Beverly Blvd, Los Angeles, CA, USA. Email: Charles.rosser@csmc.edu. \\ Provenance: This is an Invited Editorial commissioned by Section Editor Xiao Li (Department of Urology, Jiangsu Cancer Hospital \& Jiangsu \\ Institute of Cancer Research \& Nanjing Medical University Affiliated Cancer Hospital, Nanjing, China). \\ Comment on: Gopalakrishna A, Chang A, Longo TA, et al. Dietary patterns and health-related quality of life in bladder cancer survivors. Urol Oncol \\ 2018;36:469.e21-469.e29.
}

Submitted Nov 19, 2018. Accepted for publication Dec 12, 2018.

doi: $10.21037 /$ tau.2018.12.02

View this article at: http://dx.doi.org/10.21037/tau.2018.12.02

Bladder cancer can be aggressive and develop resistance to currently available cancer therapies. An estimated 81,190 new cases of bladder cancer will be diagnosed in 2018 and 18,810 deaths from bladder cancer will occur in 2018 in the US (1). Both the absolute numbers of cases and deaths from bladder cancer have increased by $45 \%$ and $35 \%$, respectively, since $2002(2,3)$. Bladder cancer ranks as the $4^{\text {th }}$ most common cancer in men affecting males 4 times the rate as females and in the top 10 common cause of cancer deaths in men and women in the US (1). In addition, bladder cancer has a high rate of recurrence compared to other tumor types (4), thus it an ideal population for health promotion efforts.

At the center of our health promotion efforts is our diet. Dietary patterns in the general US population is noted to be high in meat (specifically red meat) and saturated fat and low in fiber, vegetables and fruits. Furthermore, caloric intake among Americans remains high. Thus, the average American diet 'needs improvement' according to the HEI2010, not only in terms of quality but in terms of quantity (5). These dietary patterns along with a more sedentary lifestyle is in part responsible for the obesity epidemic engulfing the US and the world. Approximately one-third of adults and one-fifth of children and adolescents in the U.S. are noted to be obese (6), thus obesity affects all segments of the U.S. population. Obesity has been linked to many diseases in children and has been associated with cancers in adult. Furthermore, obesity can adversely affect health-related quality of life (HRQoL) in cancer survivors $(7,8)$.
As society and medicine place greater emphasis on cancer survivorship, we must critically review the current dietary patterns of cancer patients to determine if and how changes need to be made, which could lead to a better HRQoL. Gopalakrishna et al. recently reported a fascinating large cross-sectional cohort study from Duke University determining the baseline dietary characteristics of bladder cancer survivors and demonstrate its relationship to HRQoL (9). Briefly, 953 bladder cancer survivors were mailed Diet History Questionnaire II and Functional Assessment of Cancer Therapy-Bladder Cancer. Using the Diet History Questionnaire II, the quality of the diet was assessed with the Healthy Eating Index 2010 scores. Four hundred and fifty-nine patients (48\%) returned their completed questionnaires. Mean age of responder was 74 years, $81 \%$ were men and $28 \%$ had undergone a cystectomy. It was felt that diet quantity and quality in the study population was comparable to the general US population of this age range and did not differ between responders with more advanced disease who underwent cystectomy compared to responders with lower stage disease managed conservatively. The study population was reported to have a low intake of whole grains and fat-soluble vitamin particularly vitamin D. Diet quality was noted to correlate with HRQoL. High comorbidity index correlated with reduced HRQoL (9).

More data support the concept that diet may influence outcomes following a cancer diagnosis. For example, breast cancer survivors who have better overall diet quality 
also noted improved HRQoL (10). Overall the study by Gopalakrishna et al. confirm the results that eating healthier is better for bladder cancer survivors (9). Limitations of these studies include (I) select population being evaluated, (II) limited follow-up and (III) multifactorial nature of HRQoL.

Furthermore, a meta-analysis of three studies with an aggregate of 9,966 subjects suggested that a diet low in saturated fat can reduce the risk of breast cancer recurrence by nearly $25 \%$ as well as reduce all-cause mortality by approximately $20 \%$ (11). In another meta-analysis of four studies with an aggregate of 3,675 subjects, researchers noted that a diet high in saturated fats increased breast cancer-specific mortality (12). A meta-analysis of 56 observational studies with an aggregate of $1,784,404$ cancer survivors with different tumor types noted that a greater adherence to a healthy diet comprised of nuts, beans, fruits, vegetables, cereal grains, olive oil and fish was associated with lower all-cause cancer mortality for gastric, prostate, liver, head and neck, breast, prostate, colorectal, pancreatic and respiratory cancers (13). Subjects with a history of colorectal cancer who consumed a Western diet (i.e., high intake of meat, fat, refined grains and desserts) demonstrated elevated risk of tumor recurrence as well as overall mortality compared to those with a more prudent diet comprised of vegetables, fruit, fish and poultry in a prospective study of 1,009 subjects (14). Two other prospective cohort studies in subjects with a history of breast cancer reported similar findings $(10,15)$. Thus, dietary changes may have the potential to improve survival rates in our cancer patients.

American Cancer Society published guidelines for cancer survivors that recommend increased whole grain, vegetable and fruit consumption and reduction in consumption of red and processed meats (16). Prior epidemiologic studies of diet have identified improved survival after cancer with increased intake of vegetables and fruits $(17,18)$, while a plant-based diet has been shown to decrease systemic inflammation in newly diagnosed cancer patients (19). High levels of non-adherence to healthy diet patterns have been found across all ethnic groups in cancer survivors $(20,21)$. Thus, a more concerted effort is needed within our survivorship clinics to assess current diets and to implement and monitor a plan to foster healthy eating habits.

As one could image, the HRQoL of our bladder cancer patients may be affected by factors other than dietary habits. Two key components to this multifactorial of HRQoL include smoking cessation and physical exercise.
As noted in the Institution of Medicine (IOM) report (22), over $30 \%$ of all cancers are caused by smoking, thus there is a very good chance that a cancer survivor is a current smoker. Etiology of bladder cancer has been linked to exogenous and environmental risk factors. The best-known risk factors in Western societies being tobacco use. In fact, the majority of epidemiologic investigations of bladder cancer etiology has focused on cigarette smoking and has demonstrated a 3 -fold increase in risk associated with cigarette smoking as well as evidence of a clear cigarette dose-response relationship (23-26). Moreover, if cigarette smokers quit, their risk of developing bladder cancer declines dramatically to $30 \%$ after $1-4$ years and then decline over $60 \%$ after 25 years (24). Persistent tobaccouse after diagnosis and treatment has been associated with suboptimal outcomes such as, increased treatment complications, progressive disease, new secondary tumors and increased comorbidity $(27,28)$. Therefore, smoking cessation counseling and treatment planning should play a substantial role for cancer survivors to enable them to quit smoking (29).

The current dogma is that regular physical activity is advantageous for cardiovascular health by lowering systolic and diastolic blood pressure, improving sensitivity to insulin, and producing a more favorable serum lipid profile (30). However, these same benefits can improve cancer survivors' outcomes. For example, Courneya et al. examined the effects of aerobic exercise $v s$. resistance exercise $v s$. usual physical fitness care on HRQoL and other psychosocial parameters in a study of 242 breast cancer survivors immediately prior to beginning adjuvant chemotherapy. They noted favorable outcomes when aerobic or resistance exercise training was performed (i.e., improved HRQoL and completion of greater cycles of chemotherapy) in comparison to usual care (31). In a previous article describing their large crosssectional cohort study conducted at Duke University, Gopalakrishna et al. reported bladder cancer survivors who noted "high" physical activity had markedly higher HRQoL compared to those who noted "low" physical activity. Physical activity had a positive correlation to HRQoL (32). Thus, our survivorship clinics should increase attention on the role of exercise interventions as an adjunct activity for cancer survivors during therapy and after the completion of therapy.

As global cancer survival rates continue to improve, there is an increased unmet need to identify and address modifiable lifestyle factors among cancer survivors in order to improve long-term outcomes. Thus, failure to 
meet guidelines for healthy lifestyle may adversely affect HRQoL. Maintaining a healthy lifestyle by ensuring a better overall diet quality, tobacco cessation and exercise interventions may correlate with an improved HRQoL in bladder cancer patients, and more broadly all cancer patients. Thus, greater attention to these factors must be stressed in our survivorship clinics.

\section{Acknowledgements}

None.

\section{Footnote}

Conflicts of Interest: The author has no conflicts of interest to declare.

\section{References}

1. Siegel RL, Miller KD, Jemal A. Cancer Statistics, 2018. CA Cancer J Clin 2018;68:7-30.

2. Jemal A, Thomas A, Murray T, et al. Cancer Statistics, 2002. CA Cancer J Clin 2002;52:23-47.

3. The Global Cancer Observatory (GCO) is an interactive web-based platform presenting global cancer statistics to inform cancer control and research. Available online: http://globocan.iarc.fr/Pages/summary_table_site_sel.aspx on January 15, 2017.

4. Pashos CL, Botteman MF, Laskin BL, et al. Bladder cancer: epidemiology, diagnosis, and management. Cancer Pract 2002;10:311-22.

5. Healthy Eating Index (HEI). Available online: https:// www.cnpp.usda.gov/healthyeatingindex

6. Flegal KM, Carroll M, Ogden C, et al. Prevalence and trends in obesity among US adults, 1999-2008. JAMA 2010;303:235-41.

7. Mitchell NS, Catenacci VA, Wyatt HR, et al. Obesity: overview of an epidemic. Psychiatr Clin North Am 2011;34:717-32.

8. Roberts AL, Fisher A, Smith L, et al. Digital health behaviour change interventions targeting physical activity and diet in cancer survivors: a systematic review and metaanalysis. J Cancer Surviv 2017;11:704-19.

9. Gopalakrishna A, Chang A, Longo TA, et al. Dietary patterns and health-related quality of life in bladder cancer survivors. Urol Oncol 2018;36:469.e21-469.e29.

10. George SM, Ballard-Barbash R, Shikany JM, et al. Better postdiagnosis diet quality is associated with reduced risk of death among postmenopausal women with invasive breast cancer in the women's health initiative. Cancer Epidemiol Biomarkers Prev 2014;23:575-83.

11. Xing MY, Xu SZ, Shen P. Effect of low-fat diet on breast cancer survival: a meta-analysis. Asian Pac J Cancer Prev 2014;15:1141-4.

12. Brennan SF, Woodside JV, Lunny PM, et al. Dietary fat and breast cancer mortality: a systematic review and metaanalysis. Crit Rev Food Sci Nutr 2017;57:1999-2008.

13. Schwingshackl L, Hoffmann G. Adherence to Mediterranean diet and risk of cancer: an updated systematic review and meta-analysis of observational studies. Cancer Med 2015;4:1933-47.

14. Meyerhardt JA, Niedzwiecki D, Hollis D, et al. Association of dietary patterns with cancer recurrence and survival in patients with stage III colon cancer. JAMA 2007;298:754-64.

15. Vrieling A, Buck K, Seibold P, et al. Dietary patterns and survival in German postmenopausal breast cancer survivors. Br J Cancer 2013;108:188-92.

16. Kushi LH, Doyle C, McCullough M, et al. American Cancer Society guidelines on nutrition and physical activity for cancer prevention. CA Cancer J Clin 2012;62:30-67.

17. Kroenke CH. Dietary Patterns and Survival After Breast Cancer Diagnosis. J Clin Oncol 2005;23:9295-303.

18. Kenfield SA, DuPre N, Richman E, et al. Mediterranean Diet and Prostate Cancer Risk and Mortality in the Health Professionals Follow-up Study. Eur Urol 2014;65:887-94.

19. Arthur AE, Peterson K, Shen J, et al. Diet and proinflammatory cytokine levels in head and neck squamous cell carcinoma. Cancer 2014;120:2704-12.

20. McCullough ML, Patel A, Kushi L, et al. Following Cancer Prevention Guidelines Reduces Risk of Cancer, Cardiovascular Disease, and All-Cause Mortality. Cancer Epidemiol Biomarkers Prev 2011;20:1089-97.

21. Byrd DA, Agurs-Collins T, Berrigan D, et al. Racial and Ethnic Differences in Dietary Intake, Physical Activity, and Body Mass Index (BMI) Among Cancer Survivors: 2005 and 2010 National Health Interview Surveys (NHIS). J Racial Ethn Health Disparities 2017;4:1138-46.

22. Hewitt M, Greenfield S, Stovall EL. Institute of Medicine and National Research Council: From Cancer Patient to Cancer Survivors: Lost in Transition. Washington, DC: National Academies Press, 2005.

23. Josephson DY, Pasin E, Stein JP. Superficial bladder cancer: part 1. Update on etiology, classification and natural history. Expert Rev Anticancer Ther 2006;6:1723-34. 
24. Brennan P, Bogillot O, Cordier S, et al. Cigarette smoking and bladder cancer in men: a pooled analysis of 11 casecontrol studies. Int J Cancer 2000;86:289-94.

25. Zeegers MP, Kellen E, Buntinx F, et al. The association between smoking, beverage consumption, diet and bladder cancer: a systematic literature review. World J Urol 2004;21:392-401.

26. Pelucchi C, Bosetti C, Negri E, et al. Mechanisms of disease: The epidemiology of bladder cancer. Nat Clin Pract Urol 2006;3:327-40.

27. Gritz ER, Dresler C, Sarna L. Smoking, the missing drug interaction in clinical trials: ignoring the obvious. Cancer Epidemiol Biomarkers Prev 2005;14:2287-93.

28. Lin K, Patel SG, Chu PY, et al. Second primary malignancy of the aerodigestive tract in patients treated for cancer of the oral cavity and larynx. Head Neck 2005;27:1042-8.

Cite this article as: Rosser CJ. Nutritional implications for quality of life in bladder cancer survivors. Transl Androl Urol 2018;7(Suppl 6):S688-S691. doi: 10.21037/tau.2018.12.02
29. Gritz ER, Vidrine DJ, Lazev AB. Smoking cessation in cancer patients: Never too late to quit. In: Given B, Given CW, Champion V, et al. editors. Evidence-Based Interventions in Oncology. New York: Springer Publishing Company, 2003:107-40.

30. Nystoriak MA, Bhatnagar A. Cardiovascular Effects and Benefits of Exercise. Front Cardiovasc Med 2018;5:135.

31. Courneya KS, Segal RJ, Mackey JR, et al. Effects of aerobic and resistance exercise in breast cancer patients receiving adjuvant chemotherapy: a multicenter randomized controlled trial. J Clin Oncol 2007;25:4396-404.

32. Gopalakrishna A, Longo TA, Fantony JJ, et al. Physical activity patterns and associations with health-related quality of life in bladder cancer survivors. Urol Oncol 2017;35:540.e1-540.e6. 